\title{
Molecular Chaperone GRP94/GP96 in Cancers: Oncogenesis and Therapeutic Target
}

\author{
Xiaofeng Duan ${ }^{1 \dagger}$, Stephen Iwanowycz ${ }^{1 \dagger}$, Soo $\mathrm{Ngoi}^{2}$, Megan Hill ${ }^{2}$, Qiang Zhao ${ }^{3}$ \\ and Bei Liu ${ }^{1,2,4 *}$
}

OPEN ACCESS

Edited by:

Edward Wenge Wang,

City of Hope National Medical Center,

United States

Reviewed by:

Brian Blagg,

University of Notre Dame,

United States

Bing Su,

Shanghai Jiao Tong University School of Medicine, China

*Correspondence:

Bei Liu

bei.liu@osumc.edu

${ }^{\dagger}$ Present address:

Xiaofeng Duan,

Department of Minimally Invasive

Esophageal Surgery, Tianjin Medical

University Cancer Institute and

Hospital, Tianjin, China

Stephen Iwanowycz,

Nilogen Oncosystems, Tampa, FL,

United States

Specialty section:

This article was submitted to

Cancer Molecular Targets and Therapeutics,

a section of the journal

Frontiers in Oncology

Received: 16 November 2020

Accepted: 10 March 2021

Published: 09 April 2021

Citation:

Duan X, Iwanowycz S, Ngoi S, Hill M,

Zhao Q and Liu B (2021) Molecular Chaperone GRP94/GP96 in Cancers: Oncogenesis and Therapeutic Target.

Front. Oncol. 11:629846.

doi: 10.3389/fonc.2021.629846

\begin{abstract}
${ }^{1}$ Department of Microbiology \& Immunology, Hollings Cancer Center, Medical University of South Carolina, Charleston, SC, United States, ${ }^{2}$ Division of Hematology, Department of Internal Medicine, The Ohio State University Comprehensive Cancer Center, Columbus, $\mathrm{OH}$, United States, ${ }^{3}$ Department of Pediatric Oncology, Tianjin Medical University Cancer Institute and Hospital, National Clinical Research Center for Cancer, Key Laboratory of Cancer Prevention and Therapy of Tianjin, Tianjin Clinical Research Center for Cancer, Tianjin, China, ${ }^{4}$ The Pelotonia Institute for Immuno-Oncology at The Ohio State University Comprehensive Cancer Center, Columbus, $\mathrm{OH}$, United States
\end{abstract}

During tumor development and progression, intrinsic and extrinsic factors trigger endoplasmic reticulum (ER) stress and the unfolded protein response, resulting in the increased expression of molecular chaperones to cope with the stress and maintain tumor cell survival. Heat shock protein (HSP) GRP94, also known as GP96, is an ER paralog of HSP90 and has been shown to promote survival signaling during tumor-induced stress and modulate the immune response through its multiple clients, including TLRs, integrins, LRP6, GARP, IGF, and HER2. Clinically, elevated expression of GRP94 correlates with an aggressive phenotype and poor clinical outcome in a variety of cancers. Thus, GRP94 is a potential molecular marker and therapeutic target in malignancies. In this review, we will undergo deep molecular profiling of GRP94 in tumor development and summarize the individual roles of GRP94 in common cancers, including breast cancer, colon cancer, lung cancer, liver cancer, multiple myeloma, and others. Finally, we will briefly review the therapeutic potential of selectively targeting GRP94 for the treatment of cancers.

Keywords: endoplasmic reticulum stress, cancer, chaperone, GRP94/GP96, biomarker, therapeutic target

\section{INTRODUCTION}

Glucose regulated protein 94 (GRP94), also known as GP96, is a stress-inducible molecular chaperone that belongs to the heat shock protein (HSP) 90 family (1). GRP94 is upregulated in many stress conditions that disturb endoplasmic reticulum (ER) homeostasis (2). A wide range of stressful conditions exists within the tumor microenvironment, including hypoxia, redox homeostasis dysregulation, altered cell metabolism, acidosis, and genetic lesions leading to the production of mutated proteins, high rates of proliferation, and increased protein synthesis (3). Activation of the unfolded protein response (UPR) leads to the up-regulation of pro-survival proteins involved in angiogenesis, folding capacity, redox protection, or degradation of unfolded proteins (4). However, when the activation of this response is prolonged, it can also result in cell death. GRP94 plays a critical role in regulating the balance between cancer cell survival and death 
through sustaining ER protein folding capacity, maintaining ER stress sensors, and repressing ER-associated pro-apoptotic machinery (Figure 1B).

Moreover, GRP94 is responsible for chaperoning multiple proteins that have been reported to play essential roles in immune response and promoting cancer development, including Toll-like receptors (TLRs) (5-8), the majority of $\alpha$ and $\beta$ integrin subunits $(7,9)$, Wnt co-receptor low-density lipoprotein receptor-related protein 6 (LRP6) $(9,10)$, glycoprotein A repetitions predominant (GARP) (11-15), Insulin-like growth factor (IGF) (16-18), as well as platelet glycoprotein Ib-IX-V complex (19) (Figure 1A).

Using a genetic strategy, depletion of GRP94 from specific cells reveals that GRP94 promotes tumorigenesis in multiple myeloma (10), liver cancer (20-22), colon cancer $(23,24)$, and endometrial carcinoma (25). An elevated level of GRP94 has also been reported in many cancers (26-29) and is associated with a more aggressive tumor phenotype. This review will mainly focus on the involvement of GRP94 in cancer development and progression and its potential as a diagnostic biomarker as well as a therapeutic target.

\section{ONCOGENIC NATURE OF GRP94 CLIENTS}

GRP94 is a master ER chaperone that plays a role in protein quality control in response to stress, inflammation, and cancer through its client protein networks, such as LRP6-Wnt, GARPTGF- $\beta$ signaling pathways, etc. $(9,10,23)$. The Wnt signal network plays a critical role in regulating cell differentiation, proliferation, and fate $(30,31)$. The bindings of Wnt to Frizzled and LRP 5 and 6 stabilize $\beta$-catenin, a major mediator in the canonical Wnt signaling pathway $(32,33)$. GRP94 is a critical chaperone for the Wnt co-receptor LRP6. Without GRP94, LRP6 fails to export from the ER to the cell surface, resulting in a profound loss of canonical Wnt signaling and causing a fast and severe compromise in intestinal homeostasis. This study uncovered the role of GRP94 in coordinating intestinal homeostasis through chaperoning LRP6, placing the canonical Wnt-signaling pathway under the direct regulation of the general protein quality control machinery in the ER (9). Additionally, specific deletion of GRP94 in macrophages protects mice from inflammation-associated colon tumorigenesis partially by the protection of gut epithelium from $\beta$-catenin mutation and stabilizes the DNA repair pathway (23). Furthermore, we demonstrated that GRP94 is required for multiple myeloma cell survival, which is mediated in part by the Wnt target survivin in a murine model of multiple myeloma (10). Also, we found that GRP94 is highly expressed in malignant plasma cells in human multiple myeloma, and the higher levels of GRP94 have a significant association with a worse clinical stage in myeloma (34).

GARP is essential to the expression of latent TGF- $\beta$ (LTGF- $\beta$ ) on the surface of Foxp $3^{+}$regulatory T cells (Tregs) and activated platelets (35). Zhang et al. demonstrated that GARP is a client protein of GRP94 (11). In the absence of GRP94, GARP is unable to exit the ER because of incorrect protein folding. Specific deletion of GRP94 in Tregs resulted in both membraneassociated LTGF- $\beta$ and secreted form of active TGF- $\beta$ from Tregs being significantly reduced (11) (Figure 1C). Also, platelet-specific deletion of GARP blunted systemic active TGF- $\beta$ and induced anti-tumor immunity against both melanoma and colon cancer (13). Furthermore, Salem et al. demonstrated that Treg cells lacking GARP were unable to suppress pathogenic $\mathrm{T}$ cell responses, promoted inflammation, and improved anti-tumor immunity in the inflammationassociated colon cancer model (14). Moreover, Metelli et al. found that GARP is highly expressed in human breast cancers compared with normal breast tissue. Overexpression of GARP in normal mammary gland epithelial cells increased TGF- $\beta$ bioactivity and promoted malignant transformation in immune-deficient mice (12).

GRP94 is a master chaperone for a variety of integrins and all TLRs except TLR3 $(5-9,36,37)$. Integrins are transmembrane receptors that facilitate cell-extracellular matrix interaction and signal transduction by modulating the cell signaling pathways of transmembrane protein kinases that can promote cell transformation and tumor progression $(38,39)$. TLRs are a class of proteins that recognize the pathogen and damage associated-molecular patterns and play a key role in innate and adaptive immune responses. TLRs are localized either on cell surfaces (TLR1, 2, 4, 5, and 6) or in the endosomes (TLR 3, 7, 8, and 9). Surface TLRs are responsible for primarily recognizing bacteria components. Intracellular TLRs recognize nucleic acids such as TLR3 for dsRNA, TLR7/8 for ssRNA, and TLR9 is the receptor for unmethylated DNA enriched with the CpG motif (40, 41). Both immune cells and tumor cells express TLRs. Immune cells of the myeloid and lymphoid lineages express TLRs to recognize pathogenic components or cellular debris and activate the immune system through the secretion of cytokines and chemokines, thereby recruiting immune cells into the tumor microenvironment and playing a key role in innate and adaptive immune responses (42).

Accumulating evidence demonstrates that the TLR signaling can be a double-edged sword in the tumor microenvironment (42-44). TLRs can manifest either pro-or anti-tumor activities depending on the tumor-infiltrating immune cells and cancer type. However, controversies exist regarding some TLRs in experimental tumor models (45). The TLR stimulation in an experimental tumor model has an anti-tumor effect by directing immune cells to a tumor site or reducing tumor progression by enhancing tumor cell apoptosis. On the contrary, TLRs expressed by tumor cells have been widely associated with tumor progression. TLR2 plays both anti- and pro-tumor roles depending on its expression on immune cells or tumors. Lowe et al. showed that TLR2 ${ }^{-/-}$mice developed more tumors in a colitis-associated colorectal tumor mouse model (46). However, specific deletion of TLR2 in epithelial cells protects $\mathrm{APC}^{\mathrm{min} /+}$ mice from adenomas and delayed the onset of mammary tumor development (47). A recent study also showed that the tumor expressing high level of TLR2 and TLR4 in colorectal cancer 
A

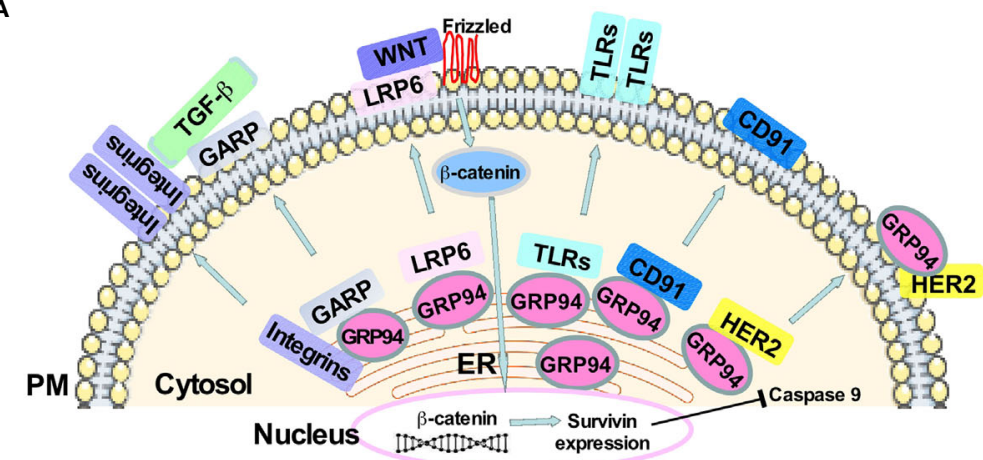

B

Tumor intrinsic factors
- Hypoxia
- ROS
- Glucose starvation
- Acidosis
- Mutated proteins
- Rapid cell proliferation
- Increased proteins

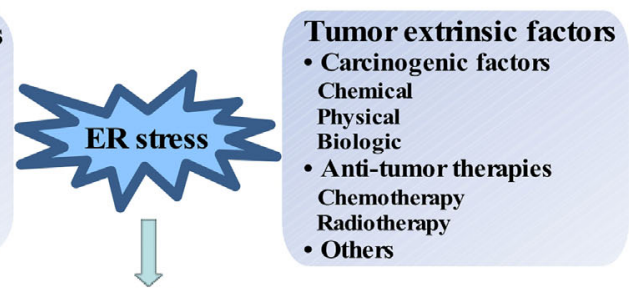

Survival

- Angiogenesis

- Chemoresistance

- Inflammation

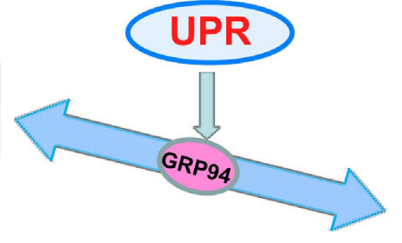

Death

- Apotosis

- Autophagy

C

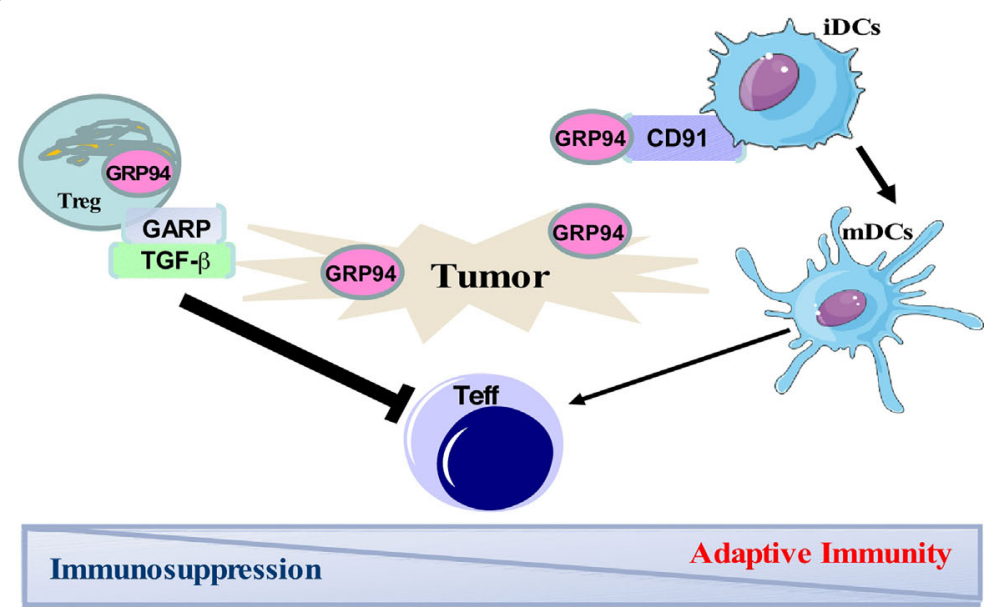

FIGURE 1 | GRP94 major client network, the role of GRP94 in balancing cancer-induced ER stress responses, and immune regulation in the tumor microenvironment. (A) Major clients of GRP94 and its role in different signaling pathways. (B) Both intrinsic and extrinsic stress conditions exist in the tumor microenvironment and trigger ER stress and UPR. Activation of UPR leads to the up-regulation of pro-survival signaling involved in angiogenesis, folding capacity, redox protection, and degradation of unfolded proteins to keep the cell surviving. However, when the UPR is prolonged, it can also result in cell death through apoptosis and autophagy. GRP94 is a downstream molecule of UPR. The increase of GRP94 is responsible for strengthening pro-survival signaling to promote tumor cell survival and aggression. (C) Surface GRP94 is involved in DC maturation via a cell surface receptor CD91. Peptides chaperoned by GRP94 can be presented to cytotoxic T lymphocytes and initiate antigen-specific T-cell responses to cancer. Also, GARP is translocated to the cell surface with the help of GRP94, which then activates latent TGF- $\beta$ in regulatory T cell (Tregs). Tregs then mediate the suppression of effector T cells leading to immunosuppression. 
patients was associated with a worse disease (48). Another study showed that stimulation of TLR2 promotes TLR2 positive squamous carcinoma cell growth (49). However, Reilley et al. showed that local injection of TLR9 agonist improved checkpoint blockade immunotherapies in poorly immunogenic melanoma (50). Also, Bellmann et al. reported that a clinical approved TLR7 agonist increased activation of tumor-infiltrating $\mathrm{T}$ and NK cells, and delayed melanoma cells' resistance to BRAF inhibitor (51). Thus, care must be taken while designing anticancer drugs targeting TLRs due to their dual role.

Human epidermal growth factor receptor-2 (HER2) is a receptor tyrosine kinase (RTK). Overexpression/amplification of HER2 has been shown in different cancers and is associated with worse clinical outcomes. HER2-targeted therapies have been used in the treatment of HER2-positive breast cancer, gynecologic malignancies, and other cancers (52-54). Interestingly, Chavany et al. demonstrated that GRP94 modulates HER2 intracellular trafficking and stability (55). Later on, Patel et al. discovered that GRP94 is associated with HER2 and stabilizes this protein at the plasma membrane (PM) in the HER2-positive breast cancer cells (56). Li et al. further demonstrated that GRP94 interacts with HER2 and facilities HER2 dimerization on the PM. Overexpression of GRP94 on the PM promotes the growth of HER2-positive breast cancer. Targeting GRP94 with a monoclonal antibody inhibits tumor growth (57). These studies indicate that molecule chaperone GRP94 and its clients play a pivotal role in cancer initiation and development.

\section{SURFACE EXPRESSION OF GRP94 AND TUMOR IMMUNOGENICITY}

GRP94/GP96 normally resides in the lumen of the ER. However, it can be translocated to the cell surface under stress and other conditions such as bacterial infection $(58,59)$ and in the tumor microenvironment $(60,61)$. GRP94 is a peptide-binding protein and stimulate an anti-tumor immune response (62). The selective surface expression of GRP94 on some immune cells in different vertebrate classes is consistent with an ancestral immunological role of GRP94 as a danger-signaling molecule (61).

Dendritic cells (DCs) are professional antigen-presenting cells (APCs) and are central to the regulation, maturation, and maintenance of cellular immune response to cancer. After taking up antigens, immature DCs differentiate into mature DCs that prime naive $\mathrm{T}$ cells and initiate antigen-specific $\mathrm{T}$-cell responses to tumors (63). Zheng et al. discovered that surface expression of GRP94 on tumor cells is involved in DC maturation and activation as well as increases tumor immunogenicity to suppress tumor growth through T lymphocytes (64). Furthermore, cell surface expression of GRP94 enhances cross-presentation of cellular antigens and the generation of tumor-specific T cell memory (65). Peptides chaperoned by GRP94 can be presented to cytotoxic T lymphocytes. Such a presentation requires the uptake of GRP94 via a cell surface receptor CD91 expressed by DCs (64) (Figure 1C).
On the other hand, cell surface GRP94 has also been found on cancer cells. A recent study found that HER2 ${ }^{+}$breast cancer cells expressed GRP94 on the PM, and GRP94 maintained the stability of HER2 to enhance downstream signaling (56). More recently, Yan et al. found that different cancer cells had distinct sensitivities to GRP94 inhibitors. More GRP94 was located on the PM in inhibitor-sensitive breast cancer cells compared with inhibitor-insensitive cancer cells. Also, the GRP94 inhibitor is preferentially bound to the PM-localized GRP94-HER2 complex. Interestingly, the hyper-N-glycosylated GRP94 at the PM contributed to the stability of GRP94-receptor tyrosine kinase complexes, which indicates that GRP94 can adopt a unique hyperglycosylated conformation to preferentially regulate growth factor receptors on tumor cells and alter tumor oncogenesis (66) (Figure 1A).

\section{THE ONTOGENETIC ROLE OF GRP94 IN CANCERS}

\section{Multiple Myeloma}

Multiple myeloma (MM) is a plasma cell malignancy. UPR plays a critical role in plasma cell differentiation and myeloma pathogenesis $(67,68)$. UPR is an evolutionally conserved mechanism that maintains protein quality control in the secretory pathway. Accumulation of misfolded proteins in the ER triggers the activation of three well-known pathways: activating transcription factor 6 (ATF6), the double-stranded RNA-activated protein kinase-like ER kinase (PERK), and the spliced form of X-box binding protein 1 (XBP1s). XBP1s and downstream ER chaperones are consistently upregulated in myeloma cells (69). Malignant plasma cells characteristically produce large amounts of proteins in the form of immunoglobulins that require ER chaperones such as GRP94 to prevent ER stress-induced cell death. Hua et al. found that the persistence of plasma cells and the development of myeloma in XBP1s-transgenic mice are critically dependent on GRP94. The addiction of myeloma cells to GRP94 was also demonstrated genetically and pharmacologically using multiple human myeloma cell lines (10). Mechanically, GRP94 is a critical chaperone for LRP6 and is essential for canonical Wnt signaling. LRP6 is required for the release of $\beta$-catenin from its destruction complex, accumulation of nuclear $\beta$-catenin, and upregulation of Wnt targets including survivin. Deletion of GRP94 compromises survivin expression, leading to its failure to safeguard mitotic spindles and the initiation of apoptosis (10, 70) through the activation of proapoptotic molecule $\mathrm{CHOP}$, which causes downstream activation of the JNK and intrinsic caspase pathways that finally lead to apoptosis of tumor cells (71). Also, Chhabra et al. found that GRP94 is highly expressed in malignant plasma cells in MM. The higher level of GRP94 is significantly associated with a worse clinical stage in MM (34). These studies uncover the critical roles of GRP94 in the initiation and progression of MM, suggesting that blockade of GRP94 is a novel therapeutic strategy against this disease. 


\section{Breast Cancer}

An early study showed that GRP94 is highly expressed in breast carcinoma cells but not in normal mammary tissue (26). CD $44^{\text {hi }}$ / $\mathrm{CD} 24^{\text {lo }}$ breast cancer stem cells represent the main driving factor in breast cancer initiation, growth, metastasis, and poor responses to anti-cancer agents. Nami et al. found that $\mathrm{CD} 44^{\mathrm{hi}} / \mathrm{CD} 24^{\mathrm{lo}}$ cells exhibited higher expression of GRP94 at both mRNA and protein levels compared to their original bulk cells (72). Dejeans et al. found that overexpression of GRP94 in breast cancers is associated with resistance to oxidative stress and the promotion of cancer cell proliferation and migration (4). The expression level of GRP94 was higher in recurrent human breast cancers than in their paired primary tumor (29). Recent studies also showed that GRP94 overexpression is associated with brain metastasis and poor survival in breast cancer patients $(73,74)$. Upregulation of the GRP94 is associated with triple-negative breast cancer brain metastasis through the Wnt- $\beta$-catenin signaling pathway (75). A recent study showed that GRP94 promoted brain metastasis by engaging pro-survival autophagy (76). Patients with infiltrated axillary lymph nodes also displayed increased expression of GRP94 protein.

Recently, Hou et al. found that GRP94 also regulated ER- $\alpha 36$ expression and signaling on the cell membrane of breast cancer. ER- $\alpha 36$ is a variant of human $\mathrm{ER} \alpha$ that is overexpressed in breast cancer and involved in tamoxifen resistance. Targeting GRP94 with siRNA or monoclonal antibody blocked the GRP94-ER- $\alpha 36$ interaction and inhibited breast cancer growth and invasion (57). Also, GRP94 can control the stability of the nascent and mature forms of HER2, an RTK, which leads to the upregulation of numerous cancer-driving signaling pathways (77). GRP94 specific inhibitors provide evidence for the role of GRP94 in maintaining the architecture of high-density HER2 formations at the plasma membrane, which is vital for proper HER2 functioning in breast cancers (56). Targeting GRP94 with a specific monoclonal antibody or peptide-based inhibitor p37 disrupted HER2 dimerization and led to HER2 degradation, which subsequently decreased tumor cell growth and increased apoptosis $(57,78)$. These results provide insights into the dependence of breast cancer cells on GRP94 for survival and suggest that GRP94 could be a potential therapeutic target for HER2 or ER- $\alpha 36$-overexpressing breast cancer.

\section{Colon Cancer}

The intestinal epithelial cells are continually replenished through the proliferation and differentiation of intestinal stem cells within the intestinal crypts (79). The interplay between ER stress and inflammation contributes to the pathogenesis of inflammatory bowel diseases and inflammation-associated colon cancer (80). Canonical Wnt signaling through the surface receptor Frizzled and its coreceptors LRP5 or LRP6 is essential for the homeostatic proliferation of epithelial cells in the gut. Unsurprisingly aberrant $\mathrm{Wnt} / \beta$-catenin signaling also plays a role in the initiation and progression of colorectal cancer, as well as its invasion and metastasis (81). Epithelial-specific GRP94 deficiency resulted in the loss of intestinal barrier function in mice dependent on canonical LRP6/Wnt-signaling (9). This study uncovered the role of GRP94 in chaperoning LRP6MesD to coordinate intestinal homeostasis, placing the canonical Wnt-signaling pathway under the direct regulation of the general protein quality control machinery in the ER (9).

Macrophages are important drivers in the development of inflammation-associated colon cancers. Using a unique macrophage-specific GRP94 deficient mouse model, Morales et al. found that macrophages promoted colitis and colitisassociated colon tumorigenesis in a GRP94-dependent manner. Strikingly, they also discovered that deletion of GRP94 in macrophages attenuated colon tumor initiation, which was correlated with reduced mutation rates of $\beta$-catenin, reduced activation of the canonical Wnt signaling, and increased efficiency of the DNA repair machinery as well as reduced expression of pro-inflammatory cytokines, including IL-17 and IL-23 in the tumor microenvironment (23). These studies reveal that GRP94 is a strategically important ER chaperone that integrates stress and innate immunity and plays a pivotal role in macrophage biology and tumor oncogenesis. Besides, GRP94 is upregulated in human metastatic colorectal cancer (28). Therefore, targeting GRP94 in macrophages may prove to be an attractive strategy for the treatment of colon cancer by regulating the Wnt and inflammatory signaling in the tumor microenvironment.

\section{Liver Cancer}

The liver is an exocrine and endocrine organ involved in the synthesis of bioactive molecules and proteins, detoxification, and metabolism, resulting in a particularly high need for adequate ER maintenance and stress-coping mechanisms. Hence, the loss of GRP94 in hepatocytes would drastically affect normal physiological functions. Chen et al. demonstrated that conditional deletion of GRP94 and PTEN from the mouse liver increased liver tumorigenesis (20). However, the GRP94 status of these tumors was not reported, leaving open a possibility of GRP94 being either a tumor suppressor or a pro-oncogenic chaperone (21). Using a similar strategy, Rachidi et al. (22) found that GRP94 maintains liver development and hepatocyte function in vivo. Deletion of GRP94 in hepatocytes promotes adaptive accumulation of long-chain ceramides, accompanied by steatosis and regeneration of residual GRP94 ${ }^{+}$hepatocytes. The need for compensatory expansion of GRP94 ${ }^{+}$cells in the GRP94 background predisposes mice to develop carcinogen-induced hepatic hyperplasia and cancer from GRP94 $4^{+}$but not GRP94 hepatocytes. They also demonstrated that both genetic and pharmacological inhibitions of GRP94 in human hepatocellular carcinoma cells perturbed multiple growth signals and attenuated their proliferation and expansion. The development of GRP94 $4^{+}$but not GRP94- tumors in the same hosts indicated that GRP94 played tumor-promoting rather than a tumorsuppressive role in liver cancer (21). Similar results were found in another study. Deletion of GRP94 resulted in liver injury, activation of oncogenic signaling, repopulation of GRP9 $4^{+}$ hepatocytes, and spontaneous development of hepatocellular carcinoma in aged mice (82).

Additionally, Lim et al. showed that the expression of GRP94 is up-regulated in hepatitis B virus-related hepatocellular 
carcinoma in humans, and is strongly correlated with vascular invasion and intrahepatic metastasis (83). Wei et al. also found that knockdown of GRP94 inhibited the growth, invasion, and metastasis of hepatocellular carcinoma cells in vivo and in vitro. The high expression of GRP94 in tumors indicated poor survival $(84,85)$. These studies show the oncologenic role of GRP94 and its potential as a prognostic indicator of liver cancer.

\section{Lung Cancer}

Cigarette smoking is the most relevant environmental risk factor associated with chronic obstructive pulmonary disease (COPD) and lung malignancies. It is well established that cigarette smoke induces ER stress, which activates UPR, and COPD subjects have intense ER stress evidenced by high expression of ER stress markers in fully differentiated human bronchial epithelial cells (86). Chronic ER stress upon exposure to cigarette smoking or other causative agents may play a pivotal role in the etiology or progression of lung cancers (87). UPR activation and enhanced ER chaperon translation, including GRP94 may promote lung cancer progression.

Wang et al. revealed that GRP94 is overexpressed in lung cancer at the mRNA and protein level and correlated with poor epithelial differentiation and tumor progression (88). Lee et al. showed that $98 \%$ of small cell lung cancer patients were GRP94 positive with moderate to high expression (27). GRP94 was also highly expressed in non-small cell lung cancer patients with brain metastasis (74). Furthermore, the upregulation of GRP94 by the interference of calcium stores can confer drug resistance to lung cancer cells against the chemotherapy agent etoposide (89). A recent study demonstrated that GRP94 is highly expressed in lung adenocarcinoma and is associated with an advanced stage of the disease as well as poor survival. Also, the GRP94 expression level was positively correlated with $\mathrm{FoxP}^{+}$regulatory $\mathrm{T}$ cells in tumors (90). Hence, targeting GRP94 will provide a new therapeutic approach to the clinical management of lung cancer with chemo-resistance.

\section{Others}

Elevated expression of GRP94 correlates with the aggressiveness of numerous other tumors, including esophageal (91), gastric (92), and pancreatic cancers (93) as well as oral carcinoma (94) and glioblastoma (95), indicating that GRP94 plays a tumorpromoting role in many different cancers. Shen et al. generated a uterus-specific GRP94 knockout mouse model and discovered that GRP94 suppressed PTEN-null driven endometrioid adenocarcinoma. Deletion of GRP94 reduced cellular proliferation through attenuating $\beta$-catenin signaling and decreasing AKT/S6 activation (25).

Tramentozzi et al. found that GRP94 was highly expressed in both gastrointestinal tumor tissues and tumor-infiltrating lymphocytes regardless of stage or anatomical location. GRP94 was also found in the plasma in stable complexes with Immunoglobulin G (IgG). The study showed that GRP94-IgG complexes are significantly increased in cancer patients compared to healthy control subjects, suggesting its potential as a diagnostic biomarker. GRP94 is over-expressed in a wide variety of both solid and hematological tumors and correlates with poor outcomes, which indicates that GRP94 is a potential diagnostic and prognostic biomarker.

\section{GRP94/GP96 AND CANCER THERAPEUTICS}

\section{Tumor Vaccine}

Mounting evidence indicates that the surface expression of GRP94/GP96 plays an integral role in shaping the immune landscape of tumors. Melendez et al. found that surface expression of GRP94 in malignant breast cells correlates with NK-mediated cytotoxicity, and the use of a GRP94 blocking antibody protected tumor cells from NK cytotoxicity (96). Zheng et al. found that overexpressed surface GRP94 on colon cancer and fibrosarcoma cells are capable of inducing maturation of dendritic cells leading to the release of proinflammatory cytokines and upregulation of antigen presentation machinery (64). Similarly, another study found that the administration of a GRP94 and Her2/neu DNA vaccine to HER2 ${ }^{+}$breast cancerbearing mice led to an increased immune response against the tumors evidenced by increased IFN- $\gamma / \mathrm{IL}-4$ levels and decreased Tregs at the tumor site (97). These studies reveal the ability of extra-cellular GRP94 to induce anti-tumor immune responses, and highlighting its potential to be used as an antigen for tumor vaccines (Table $\mathbf{1}$ ).

Immunization of tumor-bearing mice with GRP94-peptide complexes has been shown to generate effective immune responses in numerous pre-clinical and clinical settings (99, 106). Autologous tumor-derived GRP94/GP96 significantly attenuated tumor growth and improved survival in various spontaneous and carcinogen-induced cancer models. The effectiveness of the treatment was dependent on the presence of $\mathrm{CD}^{+}$and $\mathrm{CD}^{+} \mathrm{T}$ cells and NK cells (106). Similarly, placental derived GRP94 was found to bind to tumorassociated antigens such as HER2 and MUC1 and induce tumor-specific $\mathrm{T}$ cell responses (98). The therapeutic effectiveness of GRP94 complexes likely results from their ability to improve the uptake and processing of tumor antigens. Consequently, Shinagawa et al. found that delivering GRP94 complexes directly to dendritic cells ex vivo before adoptive transfer of DCs into tumor-bearing mice led to improved tumor control compared to treatment with DCs or tumor-derived GRP94 complexes alone (102). Fromm et al. reported that the secreted form of GRP94 (GRP94-Ig) and costimulator combination cellular vaccine increased antigenspecific CD8 and memory $\mathrm{T}$ cells, delayed melanoma tumor growth, and prolonged overall survival (101) (Table 1).

\section{Small Molecular Inhibitors}

GRP94 is expressed in most human cells. Therefore, specificity for cancer cells is a major concern when designing small molecular inhibitors. Identification of geldanamycin (GM) revealed the possibility of selectively targeting HSP90 within tumor cells. A more recent study showed that the purine scaffold small molecule DN401 simultaneously inhibited all HSP90 paralogs, including HSP90, TRAP1, and GRP94, and 
TABLE 1 | GRP94/GP96-targeted treatment strategies for cancers.

\begin{tabular}{|c|c|c|c|}
\hline Strategies & Phase & Effect & Reference \\
\hline \multicolumn{4}{|l|}{ Tumor Vaccine } \\
\hline Surface GP96-tumor cells & Pre-clinical study & Suppressed tumor growth through T cell-dependent mechanism. & (64) \\
\hline GRP94/Her2/neu & Pre-clinical study & Decreased Tregs at the tumor site, increasing IFN- $\gamma / \mathrm{LL}-4$ level; partial control of tumor progression. & $(97)$ \\
\hline \multicolumn{4}{|l|}{ DNA vaccine } \\
\hline Placental-derived GRP94 & Pre-clinical study & $\begin{array}{l}\text { Exhibited high immunogenicity against multiple tumors (melanoma, } \mathrm{HER}^{+} \text {, and triple negative } \\
\text { mammary tumors). }\end{array}$ & $(98)$ \\
\hline Tumor-derived GP96 & $\mathrm{I} / \mathrm{II}$ & $\begin{array}{l}\text { Increased tumor-specific immune response and prolonged the survival of patients with metastatic } \\
\mathrm{CRC} \text { and gastric cancer. }\end{array}$ & $(99,100)$ \\
\hline GP96-Ig vaccine & Pre-clinical study & $\begin{array}{l}\text { Increased Ag-specific CD8 }{ }^{+} \text {and memory } \mathrm{T} \text { cells, delayed melanoma tumor growth and prolonged } \\
\text { overall survival. }\end{array}$ & $(101)$ \\
\hline $\begin{array}{l}\text { DC vaccine with tumor- } \\
\text { derived GP96 }\end{array}$ & Pre-clinical study & Decreased the tumor growth of murine lung cancer through $\mathrm{CD}^{+} \mathrm{T}$ cells and NK cells. & $(102)$ \\
\hline \multicolumn{4}{|l|}{ Small molecule inhibitor } \\
\hline PU-WS13 & Pre-clinical study & Induced apoptosis of HER2 ${ }^{+}$breast cancer cells. & $(56)$ \\
\hline PU-WS13 & Pre-clinical study & Induced apoptosis and inhibited the growth of multiple myeloma through Wnt-Survivin pathway. & (10) \\
\hline PU-WS13 & Pre-clinical study & Inhibited the proliferation of hepatocellular carcinoma. & $(22)$ \\
\hline GRP94 Inhibitor 30 & Pre-clinical study & $\begin{array}{l}\text { Reduced the migratory capabilities of metastatic breast and prostate cancer cells through } \\
\text { degradation of integrin } \alpha 2 \text {. }\end{array}$ & (103) \\
\hline \multicolumn{4}{|l|}{ Monoclonal antibody } \\
\hline Anti-GP96 mAb & Pre-clinical study & $\begin{array}{l}\text { Increased apoptosis and suppressed the } \\
\text { HER2 }{ }^{+} \text {breast cancer cell growth. }\end{array}$ & $(57,78)$ \\
\hline Anti-GRP94 mAb W9 & Pre-clinical study & $\begin{array}{l}\text { Selectively recognized GRP94-epitope on malignant cells. Increased and restored the sensitivity of } \\
\text { BRAF-1-resistant melanoma } \\
\text { Cells. }\end{array}$ & $(104)$ \\
\hline Anti-sGRP94 lgG & Pre-clinical study & Inhibited the growth of Cetuximab-resistant CRC cells. & $(105)$ \\
\hline
\end{tabular}

synergized the anti-tumor effects with another TRAP1 inhibitor, gamitrnib (107). However, pan HSP90 inhibitors inactivate all HSP90 isoforms, including GRP94, and display severe toxicity. To improve selectivity and further reduce toxicity, Patel et al. developed novel purine-based ligands that are greater than 100fold more selective for GRP94 over HSP90 $\alpha / \beta$ (56). Based on a strategy that combined library screening of purine-scaffold compounds and structural studies, GRP94-specific inhibitors, PU-WS13, PU-H39, and PU-H54, were developed, and these inhibitors significantly induced apoptosis of human HER2 positive breast cancer cells (56). Also, Hua et al. found that PU-WS13 significantly inhibited the growth of multiple human MM cells, including those that are resistant to cytosolic HSP90 inhibitor PU-H71, doxorubicin, and proteasome inhibitor bortezomib in vitro (10). Recently, based on an extensive Structure-Activity relationship study, Patel et al. designed a new GRP94-specific inhibitor, compound 18c. Specifically, $18 \mathrm{c}$ inhibited the post-ER expression of TLR9, and also reduced the steady-state levels of HER2 kinase in HER2overexpressing breast cancer cells. When administered into tumor-bearing mice, compound $18 \mathrm{c}$ was cleared rapidly from normal tissue while being selectively retained in the tumor (108). Crowley et al. developed another series of GRP94-selective inhibitors (103). These small molecular inhibitors reduced the migratory capabilities of metastatic breast and prostate cancer cells through the degradation of integrin $\alpha 2$ and with better selectivity than their previous reported compounds (109-112) (Table 1). Recently, the Xu group developed a GRP94 selective inhibitor, Compound 54, with an IC50 of 2 nM and over 1,000fold selectivity for GRP94 versus HSP90 $\alpha$. They found that this compound has anti-inflammation efficacy in the DSS-induced colitis mouse model (113). However, Compound 54 hasn't been tested in the treatment of cancers.

\section{Monoclonal Antibody}

The therapeutic targeting of surface GRP94 in tumors has emerged with the recent development of specific monoclonal antibodies that have potent GRP94 inhibitory effects and consequent anti-tumor activities (114). Li et al. developed a GRP94 monoclonal antibody that interfered with GRP94dependent HER2 dimerization and phosphorylation in breast cancer and suppressed the HER2 ${ }^{+}$breast cancer cell growth in vitro and in vivo $(57,78)$. Moreover, Sabbatino et al. developed a novel grp94-antagonizing monoclonal antibody, W9 mAb, which selectively targets the extracellular epitope of GRP94 in malignant cells but is not detectable on normal cells. W9 mAb increased the sensitivity of human BRAF ${ }^{\mathrm{V} 600 \mathrm{E}}$ melanoma cells to BRAF inhibitors (104). Using a phage display approach, Jeoung et al. isolated an antibody binding to the cell surface of human colon cancer cells. Furthermore, they demonstrated that this antibody specifically targeted GRP94 and inhibited the growth of Cetuximab-resistant colorectal cancer (105) (Table 1). These studies lay a strong foundation for developing GRP94-targeted therapeutics for cancers in the future.

\section{CONCLUSION}

A wide range of intrinsic and extrinsic stressful conditions exists within tumors during development and progression, creating the 
need for increased chaperone expression to cope with the stress and regulate the balance between tumor cell viability and death (Figure 1B). The elevated expression of GRP94 in a variety of cancer cells correlates with an aggressive phenotype, giving it strong potential as a biomarker and therapeutic target. GRP94 has been revealed to play roles in survival signaling through its client protein network, induction of the UPR, and modulating the immune response (Figure 1). The development of a GRP94based tumor vaccine, small molecular inhibitors, and monoclonal antibodies will open new territories for cancer treatment. Nevertheless, previous attempts to target HSP90 have not been successful in clinical trials due to severe toxicity. Recently, Yan et al. discovered that GRP94 adopt a unique hyperglycosylated conformation to preferentially regulate growth factor receptors on tumor cells. GRP94 specific inhibitor PU-WS13 favorably binds to hyperglycosylated GRP94 and inhibits RTK-driven tumor growth (66). Selective inhibition of GRP94 is still a feasible targeted therapy. Up to date, the complete GRP94 client network is still unknown. Identification of GRP94 clients involved in tumor initiation and progression and the development of specific GRP94 clienttargeted therapeutics will bear fruit for the treatment of cancers.

\section{REFERENCES}

1. Lee AS. Glucose-regulated proteins in cancer: molecular mechanisms and therapeutic potential. Nat Rev Cancer (2014) 14(4):263-76. doi: 10.1038/ nrc3701

2. Ansa-Addo EA, Thaxton J, Hong F, Wu BX, Zhang Y, Fugle CW, et al. Clients and Oncogenic Roles of Molecular Chaperone gp96/ grp94. Curr Top Med Chem (2016) 16(25):2765-78. doi: 10.2174/ 1568026616666160413141613

3. Rozpedek W, Pytel D, Mucha B, Leszczynska H, Diehl JA, Majsterek I. The Role of the PERK/eIF2alpha/ATF4/CHOP Signaling Pathway in Tumor Progression During Endoplasmic Reticulum Stress. Curr Mol Med (2016) 16 (6):533-44. doi: 10.2174/1566524016666160523143937

4. Dejeans N, Glorieux C, Guenin S, Beck R, Sid B, Rousseau R, et al. Overexpression of GRP94 in breast cancer cells resistant to oxidative stress promotes high levels of cancer cell proliferation and migration: implications for tumor recurrence. Free Radic Biol Med (2012) 52(6):9931002. doi: 10.1016/j.freeradbiomed.2011.12.019.S0891-5849(11)01278-0

5. Yang Y, Liu B, Dai J, Srivastava PK, Zammit DJ, Lefrancois L, et al. Heat shock protein gp96 is a master chaperone for toll-like receptors and is important in the innate function of macrophages. Immunity (2007) 26 (2):215-26. doi: 10.1016/j.immuni.2006.12.005.S1074-7613(07)00116-1

6. Liu B, Li Z. Endoplasmic reticulum HSP90b1 (gp96, grp94) optimizes B-cell function via chaperoning integrin and TLR but not immunoglobulin. Blood (2008) 112(4):1223-30. doi: 10.1182/blood-2008-03-143107

7. Staron M, Yang Y, Liu B, Li J, Shen Y, Zuniga-Pflucker JC, et al. gp96, an endoplasmic reticulum master chaperone for integrins and Toll-like receptors, selectively regulates early $\mathrm{T}$ and B lymphopoiesis. Blood (2010) 115(12):2380-90. doi: 10.1182/blood-2009-07-233031

8. Randow F, Seed B. Endoplasmic reticulum chaperone gp 96 is required for innate immunity but not cell viability. Nat Cell Biol (2001) 3(10):891-6. doi: 10.1038/ncb1001-891

9. Liu B, Staron M, Hong F, Wu BX, Sun S, Morales C, et al. Essential roles of grp94 in gut homeostasis via chaperoning canonical Wnt pathway. Proc Natl Acad Sci U S A (2013) 110(17):6877-82. doi: 10.1073/pnas.1302933110

10. Hua Y, White-Gilbertson S, Kellner J, Rachidi S, Usmani SZ, Chiosis G, et al. Molecular chaperone gp96 is a novel therapeutic target of multiple myeloma. Clin Cancer Res (2013) 19(22):6242-51. doi: 10.1158/1078-0432.CCR-132083

\section{AUTHOR CONTRIBUTIONS}

Conceptualization, BL. Writing-original draft and literature review, XD and BL. Writing-review and editing, XD, SI, SN, $\mathrm{MH}, \mathrm{QZ}$, and BL. All authors contributed to the article and approved the submitted version.

\section{FUNDING}

This work was supported in part by NIH NCI (T32: CA193201), NIH NIAID (T32: AI 132164), NIH NCI (R01: CA193939), and NIH NIAID (U01: AI125859).

\section{ACKNOWLEDGMENTS}

We thank the past and present laboratory members for their input throughout this work. SI was supported in part by $\mathrm{NIH}$ NCI (T32: CA193201) and NIH NIAID (T32: AI 132164). BL is supported in part by NIH NCI (R01: CA193939) and NIH NIAID (U01: AI125859).

11. Zhang Y, Wu BX, Metelli A, Thaxton JE, Hong F, Rachidi S, et al. GP96 is a GARP chaperone and controls regulatory $\mathrm{T}$ cell functions. J Clin Invest (2015) 125(2):859-69. doi: 10.1172/JCI79014

12. Metelli A, Wu BX, Fugle CW, Rachidi S, Sun S, Zhang Y, et al. Surface Expression of TGFbeta Docking Receptor GARP Promotes Oncogenesis and Immune Tolerance in Breast Cancer. Cancer Res (2016) 76(24):7106-17. doi: 10.1158/0008-5472.CAN-16-1456

13. Rachidi S, Metelli A, Riesenberg B, Wu BX, Nelson MH, Wallace C, et al. Platelets subvert $\mathrm{T}$ cell immunity against cancer via GARP-TGFbeta axis. Sci Immunol (2017) 2(11):eaai7911. doi: 10.1126/sciimmunol.aai7911

14. Salem M, Wallace C, Velegraki M, Li A, Ansa-Addo E, Metelli A, et al. GARP Dampens Cancer Immunity by Sustaining Function and Accumulation of Regulatory T Cells in the Colon. Cancer Res (2019) 79(6):1178-90. doi: 10.1158/0008-5472.CAN-18-2623

15. Wallace $\mathrm{CH}, \mathrm{Wu}$ BX, Salem M, Ansa-Addo EA, Metelli A, Sun S, et al. B lymphocytes confer immune tolerance via cell surface GARP-TGF-beta complex. JCI Insight (2018) 3(7):e99863. doi: 10.1172/jci.insight.99863

16. Wanderling S, Simen BB, Ostrovsky O, Ahmed NT, Vogen SM, Gidalevitz T, et al. GRP94 is essential for mesoderm induction and muscle development because it regulates insulin-like growth factor secretion. Mol Biol Cell (2007) 18(10):3764-75. doi: 10.1091/mbc.e07-03-0275

17. Barton ER, Park S, James JK, Makarewich CA, Philippou A, Eletto D, et al. Deletion of muscle GRP94 impairs both muscle and body growth by inhibiting local IGF production. FASEB J (2012) 26(9):3691-702. doi: 10.1096/fj.11-203026

18. Argon Y, Bresson SE, Marzec MT, Grimberg A. Glucose-Regulated Protein 94 (GRP94): A Novel Regulator of Insulin-Like Growth Factor Production. Cells (2020) 9(8):1844. doi: 10.3390/cells9081844

19. Staron M, Wu S, Hong F, Stojanovic A, Du X, Bona R, et al. Heat-shock protein gp96/grp94 is an essential chaperone for the platelet glycoprotein IbIX-V complex. Blood (2011) 117(26):7136-44. doi: 10.1182/blood-2011-01330464

20. Chen WT, Tseng CC, Pfaffenbach K, Kanel G, Luo B, Stiles BL, et al. Liverspecific knockout of GRP94 in mice disrupts cell adhesion, activates liver progenitor cells, and accelerates liver tumorigenesis. Hepatology (2014) 59 (3):947-57. doi: 10.1002/hep.26711

21. Rachidi S, Sun S, Li Z. Endoplasmic reticulum heat shock protein gp96/ grp94 is a pro-oncogenic chaperone, not a tumor suppressor. Hepatology (2015) 61(5):1766-7. doi: 10.1002/hep.27400 
22. Rachidi S, Sun S, Wu BX, Jones E, Drake RR, Ogretmen B, et al. Endoplasmic reticulum heat shock protein gp96 maintains liver homeostasis and promotes hepatocellular carcinogenesis. J Hepatol (2015) 62(4):879-88. doi: 10.1016/j.jhep.2014.11.010.S0168-8278(14)00854-X

23. Morales C, Rachidi S, Hong F, Sun S, Ouyang X, Wallace C, et al. Immune chaperone gp96 drives the contributions of macrophages to inflammatory colon tumorigenesis. Cancer Res (2014) 74(2):446-59. doi: 10.1158/00085472.CAN-13-1677

24. Hong F, Wu BX, Li Z. Molecular regulation of macrophages in unleashing cancer-related inflammation. Oncoimmunology (2014) 3(1):e27659. doi: 10.4161/onci.27659.2103ONCOIMM0378

25. Shen J, Yao L, Lin YG, DeMayo FJ, Lydon JP, Dubeau L, et al. Glucoseregulated protein 94 deficiency induces squamous cell metaplasia and suppresses PTEN-null driven endometrial epithelial tumor development. Oncotarget (2016) 7(12):14885-97. doi: 10.18632/oncotarget.7450

26. Hodorova I, Rybarova S, Solar P, Vecanova J, Prokopcakova L, Bohus P, et al. Gp96 and its different expression in breast carcinomas. Neoplasma (2008) 55(1):31-5. doi: 10.1007/s00418-011-0879-y

27. Lee JH, Kang KW, Kim JE, Hwang SW, Park JH, Kim SH, et al. Differential expression of heat shock protein 90 isoforms in small cell lung cancer. Int $J$ Clin Exp Pathol (2015) 8(8):9487-93.

28. Heike M, Frenzel C, Meier D, Galle PR. Expression of stress protein gp96, a tumor rejection antigen, in human colorectal cancer. Int J Cancer (2000) 86 (4):489-93. doi: 10.1002/(SICI) 1097-0215(20000515)86:4<489::AIDIJC7>3.0.CO;2-D

29. Langer R, Feith M, Siewert JR, Wester HJ, Hoefler H. Expression and clinical significance of glucose regulated proteins GRP78 (BiP) and GRP94 (GP96) in human adenocarcinomas of the esophagus. BMC Cancer (2008) 8:70. doi: $10.1186 / 1471-2407-8-70$

30. Cong F, Schweizer L, Varmus H. Wnt signals across the plasma membrane to activate the beta-catenin pathway by forming oligomers containing its receptors, Frizzled and LRP. Development (2004) 131(20):5103-15. doi: $10.1242 / \mathrm{dev} .01318$

31. Cadigan KM, Liu YI. Wnt signaling: complexity at the surface. J Cell Sci (2006) 119(Pt 3):395-402. doi: 10.1242/jcs.02826

32. Sukhdeo K, Mani M, Zhang Y, Dutta J, Yasui H, Rooney MD, et al. Targeting the beta-catenin/TCF transcriptional complex in the treatment of multiple myeloma. Proc Natl Acad Sci U States America (2007) 104(18):7516-21. doi: 10.1073/pnas.0610299104

33. Gan XQ, Wang JY, Xi Y, Wu ZL, Li YP, Li L. Nuclear Dvl, c-Jun, betacatenin, and TCF form a complex leading to stabilization of beta-cateninTCF interaction. J Cell Biol (2008) 180(6):1087-100. doi: 10.1083/ jcb. 200710050

34. Chhabra S, Jain S, Wallace C, Hong F, Liu B. High expression of endoplasmic reticulum chaperone grp94 is a novel molecular hallmark of malignant plasma cells in multiple myeloma. J Hematol Oncol (2015) 8:77. doi: 10.1186/ s13045-015-0177-6

35. Tran DQ, Andersson J, Wang R, Ramsey H, Unutmaz D, Shevach EM. GARP (LRRC32) is essential for the surface expression of latent TGF-beta on platelets and activated FOXP3+ regulatory T cells. Proc Natl Acad Sci U S A (2009) 106(32):13445-50. doi: 10.1073/pnas.0901944106

36. Liu B, Yang Y, Qiu Z, Staron M, Hong F, Li Y, et al. Folding of Toll-like receptors by the HSP90 paralogue gp96 requires a substrate-specific cochaperone. Nat Commun (2010) 1:79. doi: 10.1038/ncomms1070

37. Wu S, Hong F, Gewirth D, Guo B, Liu B, Li Z. The molecular chaperone gp96/GRP94 interacts with Toll-like receptors and integrins via its Cterminal hydrophobic domain. J Biol Chem (2012) 287(9):6735-42. doi: 10.1074/jbc.M111.309526

38. Cabodi S, del Pilar Camacho-Leal M, Di Stefano P, Defilippi P. Integrin signalling adaptors: not only figurants in the cancer story. Nat Rev Cancer (2010) 10(12):858-70. doi: 10.1038/nrc2967

39. Pan B, Guo J, Liao Q, Zhao Y. beta1 and beta 3 integrins in breast, prostate and pancreatic cancer: A novel implication. Oncol Lett (2018) 15(4):5412-6. doi: 10.3892/ol.2018.8076

40. Akira S, Takeda K. Toll-like receptor signalling. Nat Rev Immunol (2004) 4 (7):499-511. doi: 10.1038/nri1391

41. Fitzgerald KA, Kagan JC. Toll-like Receptors and the Control of Immunity. Cell (2020) 180(6):1044-66. doi: 10.1016/j.cell.2020.02.041
42. Urban-Wojciuk Z, Khan MM, Oyler BL, Fahraeus R, Marek-Trzonkowska $\mathrm{N}$, Nita-Lazar A, et al. The Role of TLRs in Anti-cancer Immunity and Tumor Rejection. Front Immunol (2019) 10:2388. doi: 10.3389/ fimmu.2019.02388

43. Li J, Yang F, Wei F, Ren X. The role of toll-like receptor 4 in tumor microenvironment. Oncotarget. (2017) 8:66656-67. doi: 10.18632/ oncotarget.19105

44. Cen X, Liu S, Cheng K. The Role of Toll-Like Receptor in Inflammation and Tumor Immunity. Front Pharmacol (2018) 9:878. doi: 10.3389/ fphar.2018.00878

45. Patra MC, Shah M, Choi S. Toll-like receptor-induced cytokines as immunotherapeutic targets in cancers and autoimmune diseases. Semin Cancer Biol (2020) 64:61-82. doi: 10.1016/j.semcancer.2019.05.002

46. Lowe EL, Crother TR, Rabizadeh S, Hu B, Wang H, Chen S, et al. Toll-like receptor 2 signaling protects mice from tumor development in a mouse model of colitis-induced cancer. PloS One (2010) 5(9):e13027. doi: 10.1371/ journal.pone.0013027

47. Scheeren FA, Kuo AH, van Weele LJ, Cai S, Glykofridis I, Sikandar SS, et al. A cell-intrinsic role for TLR2-MYD88 in intestinal and breast epithelia and oncogenesis. Nat Cell Biol (2014) 16(12):1238-48. doi: 10.1038/ncb3058

48. Beilmann-Lehtonen I, Bockelman C, Mustonen H, Koskensalo S, Hagstrom J, Haglund C. The prognostic role of tissue TLR2 and TLR4 in colorectal cancer. Virchows Arch (2020) 477(5):705-15. doi: 10.1007/s00428-02002833-5

49. Palani CD, Ramanathapuram L, Lam-Ubol A, Kurago ZB. Toll-like receptor 2 induces adenosine receptor $\mathrm{A} 2 \mathrm{a}$ and promotes human squamous carcinoma cell growth via extracellular signal regulated kinases (1/2). Oncotarget (2018) 9(6):6814-29. doi: 10.18632/oncotarget.23784

50. Reilley MJ, Morrow B, Ager CR, Liu A, Hong DS, Curran MA. TLR9 activation cooperates with $\mathrm{T}$ cell checkpoint blockade to regress poorly immunogenic melanoma. J Immunother Cancer (2019) 7(1):323. doi: 10.1186/s40425-019-0811-x

51. Bellmann L, Cappellano G, Schachtl-Riess JF, Prokopi A, Seretis A, Ortner $\mathrm{D}$, et al. A TLR7 agonist strengthens $\mathrm{T}$ and NK cell function during BRAFtargeted therapy in a preclinical melanoma model. Int J Cancer (2019) 146:1409-20. doi: 10.1002/ijc.32777

52. Murthy RK, Loi S, Okines A, Paplomata E, Hamilton E, Hurvitz SA, et al. Tucatinib, Trastuzumab, and Capecitabine for HER2-Positive Metastatic Breast Cancer. N Engl J Med (2019) 382(7):597-609. doi: 10.1056/NEJMoa1914609

53. Erickson BK, Zeybek B, Santin AD, Fader AN. Targeting human epidermal growth factor receptor 2 (HER2) in gynecologic malignancies. Curr Opin Obstet Gynecol (2020) 32(1):57-64. doi: 10.1097/GCO.0000000000000599

54. Oh DY, Bang YJ. HER2-targeted therapies - a role beyond breast cancer. Nat Rev Clin Oncol (2020) 17(1):33-48. doi: 10.1038/s41571-019-0268-3

55. Chavany C, Mimnaugh E, Miller P, Bitton R, Nguyen P, Trepel J, et al. p185erbB2 binds to GRP94 in vivo. Dissociation of the p185erbB2/GRP94 heterocomplex by benzoquinone ansamycins precedes depletion of p185erbB2. J Biol Chem (1996) 271(9):4974-7. doi: 10.1074/jbc.271.9.4974

56. Patel PD, Yan P, Seidler PM, Patel HJ, Sun W, Yang C, et al. Paralogselective Hsp90 inhibitors define tumor-specific regulation of HER2. Nat Chem Biol (2013) 9(11):677-84. doi: 10.1038/nchembio.1335

57. Li X, Sun L, Hou J, Gui M, Ying J, Zhao H, et al. Cell membrane gp96 facilitates HER2 dimerization and serves as a novel target in breast cancer. Int J Cancer (2015) 137(3):512-24. doi: 10.1002/ijc.29405

58. Martins M, Custodio R, Camejo A, Almeida MT, Cabanes D, Sousa S. Listeria monocytogenes triggers the cell surface expression of Gp96 protein and interacts with its $\mathrm{N}$ terminus to support cellular infection. J Biol Chem (2012) 287(51):43083-93. doi: 10.1074/jbc.M112.422568

59. Mittal R, Prasadarao NV. gp96 expression in neutrophils is critical for the onset of Escherichia coli K1 (RS218) meningitis. Nat Commun (2011) 2:552. doi: $10.1038 /$ ncomms 1554

60. Altmeyer A, Maki RG, Feldweg AM, Heike M, Protopopov VP, Masur SK, et al. Tumor-specific cell surface expression of the-KDEL containing, endoplasmic reticular heat shock protein gp96. Int J Cancer (1996) 69(4):340-9. doi: 10.1002/ (SICI) 1097-0215(19960822)69:4<340::AID-IJC18>3.0.CO;2-9

61. Robert J, Menoret A, Cohen N. Cell surface expression of the endoplasmic reticular heat shock protein gp96 is phylogenetically conserved. J Immunol (1999) 163(8):4133-9. 
62. Linderoth NA, Popowicz A, Sastry S. Identification of the peptide-binding site in the heat shock chaperone/tumor rejection antigen gp96 (Grp94). J Biol Chem (2000) 275(8):5472-7. doi: 10.1074/jbc.275.8.5472

63. Banchereau J, Briere F, Caux C, Davoust J, Lebecque S, Liu YJ, et al. Immunobiology of dendritic cells. Annu Rev Immunol (2000) 18:767-811. doi: 10.1146/annurev.immunol.18.1.767

64. Zheng H, Dai J, Stoilova D, Li Z. Cell surface targeting of heat shock protein gp96 induces dendritic cell maturation and antitumor immunity. J Immunol (2001) 167(12):6731-5. doi: 10.4049/jimmunol.167.12.6731

65. Dai J, Liu B, Caudill MM, Zheng H, Qiao Y, Podack ER, et al. Cell surface expression of heat shock protein gp96 enhances cross-presentation of cellular antigens and the generation of tumor-specific $\mathrm{T}$ cell memory. Cancer Immun (2003) 3:1.

66. Yan P, Patel HJ, Sharma S, Corben A, Wang T, Panchal P, et al. Molecular Stressors Engender Protein Connectivity Dysfunction through Aberrant NGlycosylation of a Chaperone. Cell Rep (2020) 31(13):107840. doi: 10.1016/ j.celrep.2020.107840

67. Iwakoshi NN, Lee AH, Vallabhajosyula P, Otipoby KL, Rajewsky K, Glimcher LH. Plasma cell differentiation and the unfolded protein response intersect at the transcription factor XBP-1. Nat Immunol (2003) 4(4):321-9. doi: 10.1038/ni907

68. Carrasco DR, Sukhdeo K, Protopopova M, Sinha R, Enos M, Carrasco DE, et al. The differentiation and stress response factor XBP-1 drives multiple myeloma pathogenesis. Cancer Cell (2007) 11(4):349-60. doi: 10.1016/ j.ccr.2007.02.015.S1535-6108(07)00061-X

69. Bagratuni T, Wu P, Gonzalez de Castro D, Davenport EL, Dickens NJ, Walker BA, et al. XBP1s levels are implicated in the biology and outcome of myeloma mediating different clinical outcomes to thalidomide-based treatments. Blood (2010) 116(2):250-3. doi: 10.1182/blood-2010-01-263236

70. White-Gilbertson S, Hua Y, Liu B. The role of endoplasmic reticulum stress in maintaining and targeting multiple myeloma: a double-edged sword of adaptation and apoptosis. Front Genet (2013) 4:109. doi: 10.3389/ fgene.2013.00109

71. Davenport EL, Moore HE, Dunlop AS, Sharp SY, Workman P, Morgan GJ, et al. Heat shock protein inhibition is associated with activation of the unfolded protein response pathway in myeloma plasma cells. Blood (2007) 110(7):2641-9. doi: 10.1182/blood-2006-11-053728

72. Nami B, Ghasemi-Dizgah A, Vaseghi A. Overexpression of molecular chaperons GRP78 and GRP94 in CD44(hi)/CD24(lo) breast cancer stem cells. Bioimpacts (2016) 6(2):105-10. doi: 10.15171/bi.2016.16

73. Sanz-Pamplona R, Aragues R, Driouch K, Martin B, Oliva B, Gil M, et al. Expression of endoplasmic reticulum stress proteins is a candidate marker of brain metastasis in both ErbB-2+ and ErbB-2- primary breast tumors. Am J Pathol (2011) 179(2):564-79. doi: 10.1016/j.jpath.2011.04.037.S0002-9440(11) 00465-2

74. Martinez-Aranda A, Hernandez V, Guney E, Muixi L, Foj R, Baixeras N, et al. FN14 and GRP94 expression are prognostic/predictive biomarkers of brain metastasis outcome that open up new therapeutic strategies. Oncotarget (2015) 6(42):44254-73. doi: 10.18632/oncotarget.5471

75. Smid M, Wang Y, Zhang Y, Sieuwerts AM, Yu J, Klijn JG, et al. Subtypes of breast cancer show preferential site of relapse. Cancer Res (2008) 68 (9):3108-14. doi: 10.1158/0008-5472.CAN-07-5644.68/9/3108

76. Santana-Codina N, Muixi L, Foj R, Sanz-Pamplona R, Badia-Villanueva M, Abramowicz A, et al. GRP94 promotes brain metastasis by engaging prosurvival autophagy. Neuro Oncol (2020) 22(5):652-64. doi: 10.1093/neuoncl noz198

77. Baselga J, Swain SM. Novel anticancer targets: revisiting ERBB2 and discovering ERBB3. Nat Rev Cancer (2009) 9(7):463-75. doi: 10.1038/nrc2656

78. Li X, Wang B, Liu W, Gui M, Peng Z, Meng S. Blockage of conformational changes of heat shock protein gp 96 on cell membrane by a alpha-helix peptide inhibits HER2 dimerization and signaling in breast cancer. PloS One (2015) 10 (4):e0124647. doi: 10.1371/journal.pone.0124647.PONE-D-15-04822

79. van der Flier LG, Clevers H. Stem cells, self-renewal, and differentiation in the intestinal epithelium. Annu Rev Physiol (2009) 71:241-60. doi: 10.1146/ annurev.physiol.010908.163145

80. Guo B, Li Z. Endoplasmic reticulum stress in hepatic steatosis and inflammatory bowel diseases. Front Genet (2014) 5:242. doi: 10.3389/ fgene.2014.00242
81. Qi J, Yu Y, Akilli Ozturk O, Holland JD, Besser D, Fritzmann J, et al. New Wnt/beta-catenin target genes promote experimental metastasis and migration of colorectal cancer cells through different signals. Gut (2016) 65(10):1690-701. doi: 10.1136/gutjnl-2014-307900

82. Chen WT, Ha D, Kanel G, Lee AS. Targeted deletion of ER chaperone GRP94 in the liver results in injury, repopulation of GRP94-positive hepatocytes, and spontaneous hepatocellular carcinoma development in aged mice. Neoplasia (2014) 16(8):617-26. doi: 10.1016/j.neo.2014.07.005.S1476-5586(14)00092-X

83. Lim SO, Park SG, Yoo JH, Park YM, Kim HJ, Jang KT, et al. Expression of heat shock proteins (HSP27, HSP60, HSP70, HSP90, GRP78, GRP94) in hepatitis B virus-related hepatocellular carcinomas and dysplastic nodules. World J Gastroenterol (2005) 11(14):2072-9. doi: 10.3748/wjg.v11.i14.2072

84. Wei PL, Huang CY, Tai CJ, Batzorig U, Cheng WL, Hunag MT, et al. Glucose-regulated protein 94 mediates metastasis by CCT8 and the JNK pathway in hepatocellular carcinoma. Tumour Biol (2016) 37(6):8219-27. doi: 10.1007/s13277-015-4669-3

85. Huang CY, Batzorig U, Cheng WL, Huang MT, Chen W, Wei PL, et al. Glucose-regulated protein 94 mediates cancer progression via AKT and eNOS in hepatocellular carcinoma. Tumour Biol (2016) 37(4):4295-304. doi: 10.1007/s13277-015-4254-9

86. Geraghty P, Baumlin N, Salathe MA, Foronjy RF, D'Armiento JM. Glutathione Peroxidase-1 Suppresses the Unfolded Protein Response upon Cigarette Smoke Exposure. Mediators Inflamm (2016) 2016:9461289. doi: $10.1155 / 2016 / 9461289$

87. Jorgensen E, Stinson A, Shan L, Yang J, Gietl D, Albino AP. Cigarette smoke induces endoplasmic reticulum stress and the unfolded protein response in normal and malignant human lung cells. BMC Cancer (2008) 8:229. doi: 10.1186/1471-2407-8-229

88. Wang Q, He Z, Zhang J, Wang Y, Wang T, Tong S, et al. Overexpression of endoplasmic reticulum molecular chaperone GRP94 and GRP78 in human lung cancer tissues and its significance. Cancer Detect Prev (2005) 29(6):54451. doi: $10.1016 /$ j.cdp.2005.09.010

89. Zhang L, Wang S, Wangtao, Wang Y, Wang J, Jiang L, et al. Upregulation of GRP78 and GRP94 and its function in chemotherapy resistance to VP-16 in human lung cancer cell line SK-MES-1. Cancer Invest (2009) 27(4):453-8. doi: $10.1080 / 07357900802527239$

90. Duan XF, Xin YW. Overexpression of molecule GRP94 favors tumor progression in lung adenocarcinoma by interaction with regulatory $\mathrm{T}$ cells. Thorac Cancer (2020) 11:704-12. doi: 10.1111/1759-7714.13321

91. Wang XP, Liu GZ, Song AL, Chen RF, Li HY, Liu Y. Expression and significance of heat shock protein 70 and glucose-regulated protein 94 in human esophageal carcinoma. World J Gastroenterol (2005) 11(3):429-32. doi: 10.3748/wjg.v11.i3.429

92. Zheng HC, Takahashi H, Li XH, Hara T, Masuda S, Guan YF, et al. Overexpression of GRP78 and GRP94 are markers for aggressive behavior and poor prognosis in gastric carcinomas. Hum Pathol (2008) 39(7):1042-9. doi: 10.1016/j.humpath.2007.11.009.S0046-8177(07)00614-4

93. Pan Z, Erkan M, Streit S, Friess H, Kleeff J. Silencing of GRP94 expression promotes apoptosis in pancreatic cancer cells. Int J Oncol (2009) 35(4):8238. doi: 10.3892/ijo_00000395

94. Nomura H, Uzawa K, Yamano Y, Fushimi K, Ishigami T, Kato Y, et al. Network-based analysis of calcium-binding protein genes identifies Grp94 as a target in human oral carcinogenesis. Br J Cancer (2007) 97(6):792-801. doi: 10.1038/sj.bjc.6603948

95. Hu T, Xie N, Qin C, Wang J, You Y. Glucose-regulated protein 94 is a novel glioma biomarker and promotes the aggressiveness of glioma via Wnt/betacatenin signaling pathway. Tumour Biol (2015) 36(12):9357-64. doi: 10.1007/s13277-015-3635-4

96. Melendez K, Wallen ES, Edwards BS, Mobarak CD, Bear DG, Moseley PL. Heat shock protein 70 and glycoprotein 96 are differentially expressed on the surface of malignant and nonmalignant breast cells. Cell Stress Chaperones (2006) 11(4):334-42. doi: 10.1379/CSC-187.1

97. Pakravan N, Langroudi L, Hajimoradi M, Hassan ZM. Co-administration of GP96 and Her2/neu DNA vaccine in a Her2 breast cancer model. Cell Stress Chaperones (2010) 15(6):977-84. doi: 10.1007/s12192-010-0208-8

98. Zhao B, Wang Y, Wu B, Liu S, Wu E, Fan H, et al. Placenta-derived gp96 as a multivalent prophylactic cancer vaccine. Sci Rep (2013) 3:1947. doi: 10.1038/ srep01947 
99. Mazzaferro V, Coppa J, Carrabba MG, Rivoltini L, Schiavo M, Regalia E, et al. Vaccination with autologous tumor-derived heat-shock protein gp96 after liver resection for metastatic colorectal cancer. Clin Cancer Res (2003) 9 (9):3235-45.

100. Zhang K, Peng Z, Huang X, Qiao Z, Wang X, Wang N, et al. Phase II Trial of Adjuvant Immunotherapy with Autologous Tumor-derived Gp96 Vaccination in Patients with Gastric Cancer. J Cancer (2017) 8(10):182632. doi: $10.7150 /$ jca. 18946

101. Fromm G, de Silva S, Giffin L, Xu X, Rose J, Schreiber TH. Gp96-Ig/ Costimulator (OX40L, ICOSL, or 4-1BBL) Combination Vaccine Improves T-cell Priming and Enhances Immunity, Memory, and Tumor Elimination. Cancer Immunol Res (2016) 4(9):766-78. doi: 10.1158/2326-6066.CIR-150228

102. Shinagawa N, Yamazaki K, Tamura Y, Imai A, Kikuchi E, Yokouchi H, et al. Immunotherapy with dendritic cells pulsed with tumor-derived gp96 against murine lung cancer is effective through immune response of CD8+ cytotoxic T lymphocytes and natural killer cells. Cancer Immunol Immunother (2008) 57(2):165-74. doi: 10.1007/s00262-007-0359-3

103. Crowley VM, Huard DJE, Lieberman RL, Blagg BSJ. Second Generation Grp94-Selective Inhibitors Provide Opportunities for the Inhibition of Metastatic Cancer. Chemistry (2017) 23(62):15775-82. doi: 10.1002/ chem. 201703398

104. Sabbatino EF F, Wang Y, Wang X, Villani V, Cai L, Yang L, et al. Grp94specific monoclonal antibody to counteract BRAF inhibitor resistance in BRAFV600E melanoma. J Transl Med (2015) 13(Suppl 1):K12. doi: 10.1186/ 1479-5876-13-S1-K12

105. Jeoung MH, Kim TK, Kim JW, Cho YB, Na HJ, Yoo BC, et al. AntibodyBased Targeting of Cell Surface GRP94 Specifically Inhibits CetuximabResistant Colorectal Cancer Growth. Biomolecules (2019) 9(11):681. doi: 10.3390/biom9110681

106. Tamura Y, Peng P, Liu K, Daou M, Srivastava PK. Immunotherapy of tumors with autologous tumor-derived heat shock protein preparations. Science (1997) 278(5335):117-20. doi: 10.1126/science.278.5335.117

107. Park HK, Yoon NG, Lee JE, Hu S, Yoon S, Kim SY, et al. Unleashing the full potential of Hsp90 inhibitors as cancer therapeutics through simultaneous inactivation of Hsp90, Grp94, and TRAP1. Exp Mol Med (2020) 52(1):79-91. doi: $10.1038 / \mathrm{s} 12276-019-0360-\mathrm{x}$
108. Patel HJ, Patel PD, Ochiana SO, Yan P, Sun W, Patel MR, et al. Structureactivity relationship in a purine-scaffold compound series with selectivity for the endoplasmic reticulum Hsp90 paralog Grp94. J Med Chem (2015) 58 (9):3922-43. doi: 10.1021/acs.jmedchem.5b00197

109. Crowley VM, Khandelwal A, Mishra S, Stothert AR, Huard DJ, Zhao J, et al. Development of Glucose Regulated Protein 94-Selective Inhibitors Based on the BnIm and Radamide Scaffold. J Med Chem (2016) 59(7):3471-88. doi: 10.1021/acs.jmedchem.6b00085

110. Khandelwal A, Crowley VM, Blagg BSJ. Resorcinol-Based Grp94-Selective Inhibitors. ACS Med Chem Lett (2017) 8(10):1013-8. doi: 10.1021/ acsmedchemlett.7b00193

111. Muth A, Crowley V, Khandelwal A, Mishra S, Zhao J, Hall J, et al. Development of radamide analogs as Grp94 inhibitors. Bioorg Med Chem (2014) 22(15):4083-98. doi: 10.1016/j.bmc.2014.05.075.S0968-0896(14) 00451-9

112. Mishra SJ, Ghosh S, Stothert AR, Dickey CA, Blagg BS. Transformation of the Non-Selective Aminocyclohexanol-Based Hsp90 Inhibitor into a Grp94-Seletive Scaffold. ACS Chem Biol (2017) 12(1):244-53. doi: 10.1021/acschembio.6b00747

113. Jiang F, Guo AP, Xu JC, You QD, Xu XL. Discovery of a Potent Grp94 Selective Inhibitor with Anti-Inflammatory Efficacy in a Mouse Model of Ulcerative Colitis. J Med Chem (2018) 61(21):9513-33. doi: 10.1021/ acs.jmedchem. $8 \mathrm{~b} 00800$

114. Wang Y, Wang X, Ferrone CR, Schwab JH, Ferrone S. Intracellular antigens as targets for antibody based immunotherapy of malignant diseases. Mol Oncol (2015) 9(10):1982-93. doi: 10.1016/j.molonc.2015.10.019.S1574-7891 (15)00197-0

Conflict of Interest: The authors declare that the research was conducted in the absence of any commercial or financial relationships that could be construed as a potential conflict of interest.

Copyright (c) 2021 Duan, Iwanowycz, Ngoi, Hill, Zhao and Liu. This is an open-access article distributed under the terms of the Creative Commons Attribution License (CC BY). The use, distribution or reproduction in other forums is permitted, provided the original author(s) and the copyright owner(s) are credited and that the original publication in this journal is cited, in accordance with accepted academic practice. No use, distribution or reproduction is permitted which does not comply with these terms. 